\title{
LOW REACTIVE-LEVEL LASER THERAPY IMPROVED SYSTEMIC SCLEROSIS-ASSOCIATED RAYNAUD'S PHENOMENON
}

\author{
*Taro Koyama, M.D., Ph.D. ${ }^{1}$ and Toshio Ohshiro, M.D., Ph.D. ${ }^{2}$ \\ 1: Department of Plastic and Reconstructive Surgery, Keio University School of Medicine, \\ Shinanomachi, Tokyo, Japan \\ 2: Japan Medical Laser Laboratory, Shinanomachi, Tokyo, Japan
}

\begin{abstract}
Systemic sclerosis (SSC) is sometimes associated with the appearance of Raynaud's disease due to diffuse vasculopathy associated with SSC. Low reactive-level laser therapy (LLLT) has been reported in the past to have beneficial effects in various vasculopathies, including Buerger's and Raynaud's diseases. The authors surmised that LLLT might therefore be of some assistance in the treatment of the Raynaud's component of SSC. A 30-yr old male patient with SSC was treated with a combination of bosentan and LLLT (GaAlAs diode laser, $60 \mathrm{~mW}$, continuous wave, incident power density $3 \mathrm{~W} / \mathrm{cm}^{2}$ ) in 35 treatment sessions over 24 weeks. After the final treatment session, both skin tightness and Raynaud's phenomenon had improved, whereas no progression was seen in the pulmonary fibrosis and pulmonary function did not get any worse. The results suggest that bosentan with complementary LLLT was effective for not only improving the dermal blood circulation but also preventing progression of the overall disease status in this case.
\end{abstract}

Key Words: anti-Scl-70 antibody, diode laser therapy, pulmonary fibrosis, Raynaud's disease, ROM

\section{Introduction}

\section{Systemic sclerosis}

Systemic sclerosis (SSC) is a multisystem disease classically characterized by inflammation, fibrosis, and diffuse vasculopathy. The main adverse effect of the disease is seen in the skin, resulting in thickening and tightness. Joint pain may occur as a result of fibrosis of the joint capsule, thickened tendons, and/ or erosive arthritis (1). Raynaud's phenomenon and gastrointestinal manifestations are common, while pulmonary, cardiac, and renal involvement can all adversely affect the prognosis ${ }^{(2)}$. There is no radical treatment for SSC, because the SSC-associated fibrosis and vasculopathy are irreversible. A combination of disease-modifying drugs, such as bosentan with stem cell transplantation, interferon-gamma and methotrexate may improve the natural course of SSC and drugs for organ-specific SSC-

Addressee for Correspondence:

Taro Koyama, MD PhD

Department of Plastic and Reconstructive Surgery, Keio University

35 Shinanomachi, Shinjuku-ku, Tokyo, Japan 160-8582

Tel: +81-3-3353-1211

E-mail: tarow@ff.iij4u.or.jp related manifestations are used, but no definitive combination approach has been established $(3,4)$

\section{Low reactive level laser therapy (LLLT)}

The use of LLLT has dramatically increased over the past two-and-a-half decades and in particular its efficacy in pain attenuation is now well recognized. Pain is only one of the facets treated with LLLT. Others include essential hypertension, hyperpigmentation and hypopigmentation, wound healing, bone repair, nerve repair, scar revision in suitable keloids, hypertrophic and depressed scars, and control of involuntary tonic spasm ${ }^{(5)}$. LLLT increases the arteriolar blood flow (6-8) and reduces both inflammation ${ }^{(9-18)}$ and fibrosis ${ }^{(19)}$.

Based on such investigations and the experience of one of the authors (TO) in the application of LLLT for psoriasis, erythroderma and rheumatoid arthritis, we examined and treated a 30-yr-old man with systemic sclerosis, interstitial pulmonary fibrosis and Raynaud's phenomenon with bosentan in combination with LLLT.

Manuscript received: July 2007

Accepted for publication: July 2007 

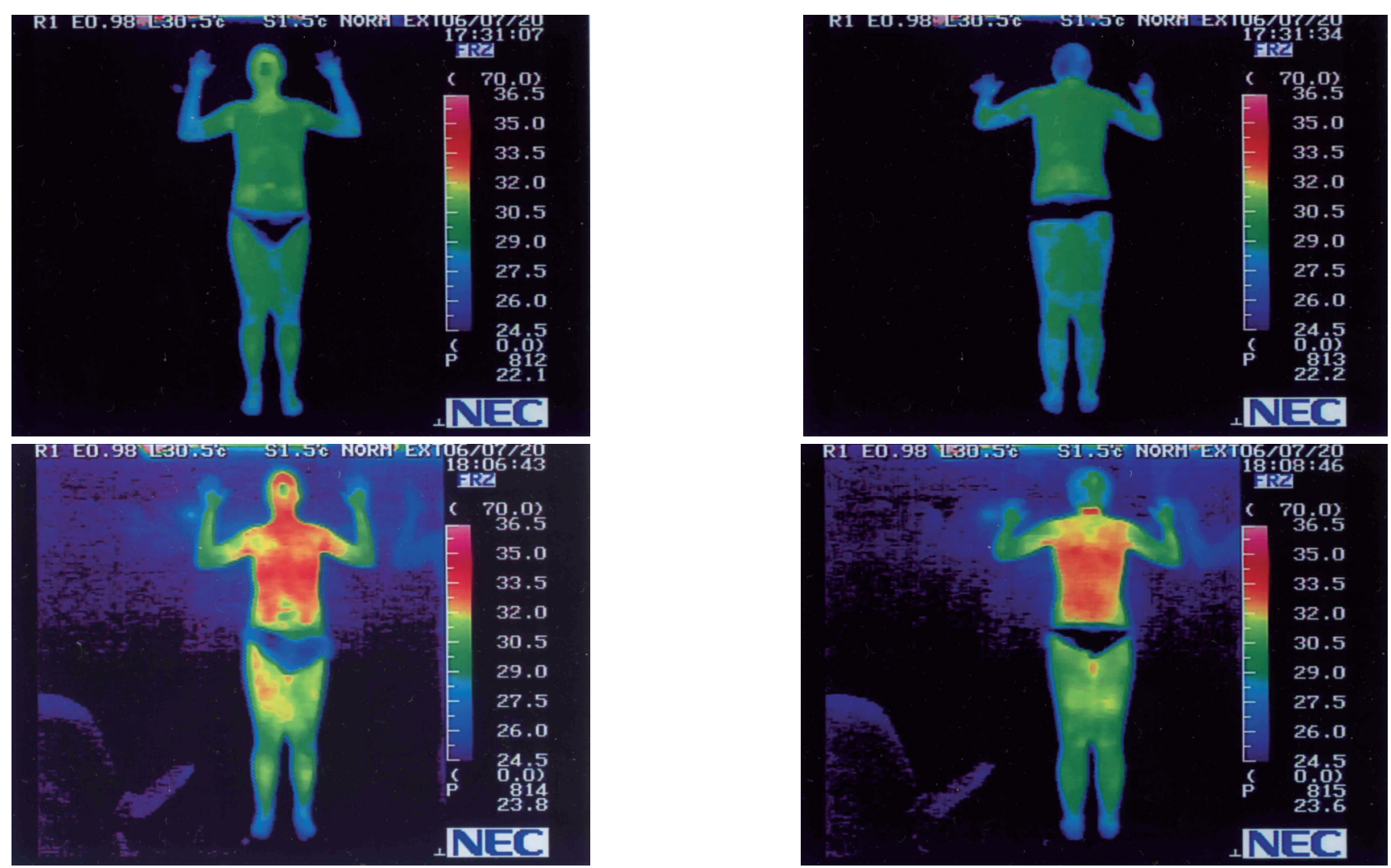

Fig . 1: Thermography taken before (above) and 5 min after (below) LLLT. Skin temperature before LLLT was cold (upper images) and improved by several degrees Celsius following LLLT (lower images).
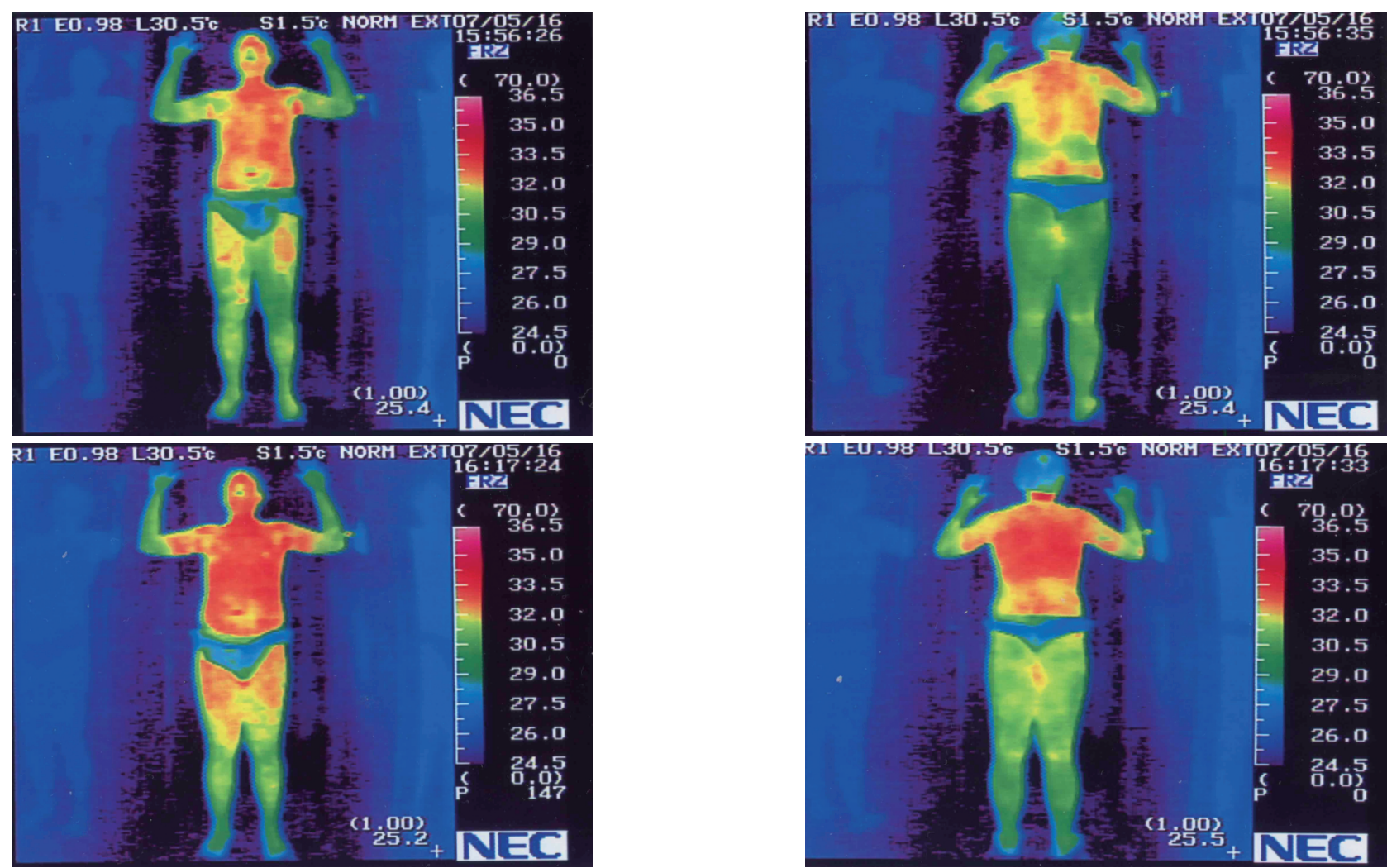

Fig. 2: Thermography taken four months before (upper images) and after the final treatment (lower images) in the LLLT series. of Skin temperature improvement had been maintained for 1 week from the previous treatment session, compared with the baseline (cf. upper images, Fig. 1) 


LLLE CASE REPORT

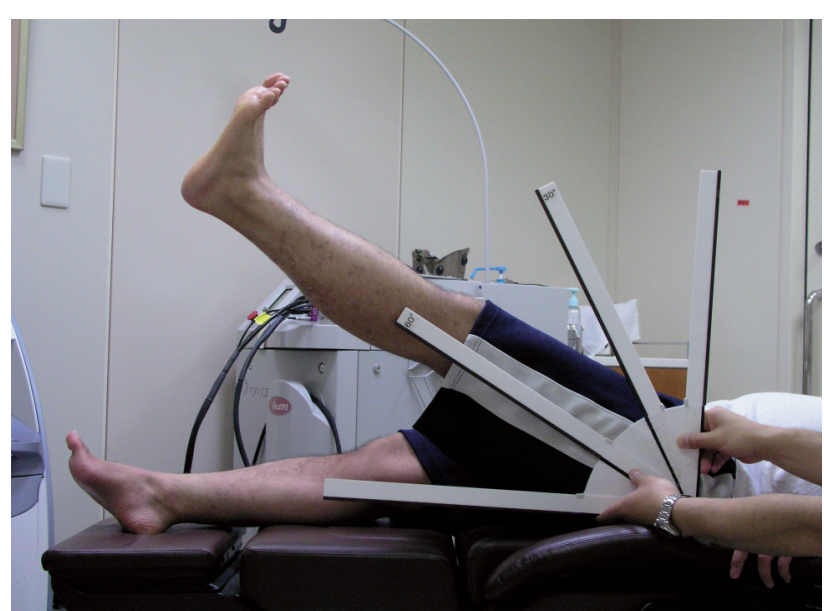

(a): ROM of the left hip joint was $30^{\circ}$ before LLLT.

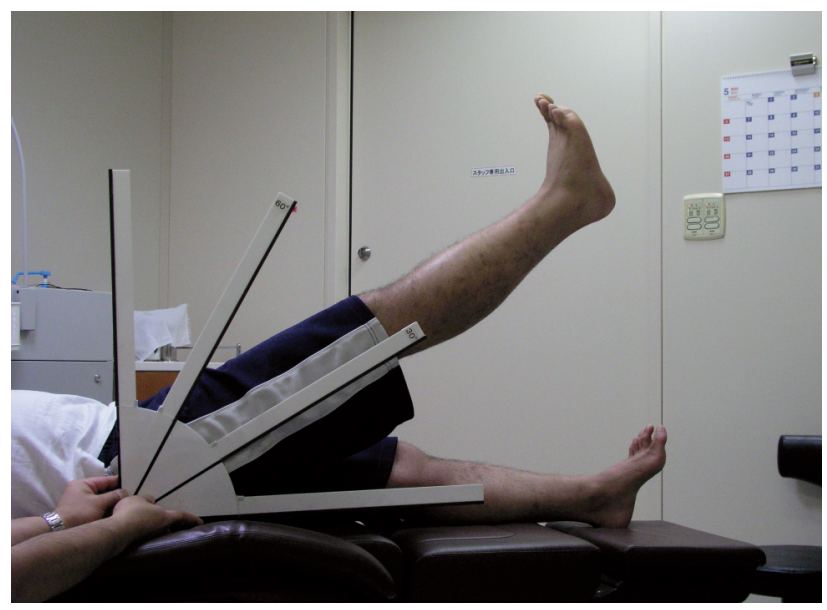

(c): ROM of the right hip joint was $30^{\circ}$ before LLLT.

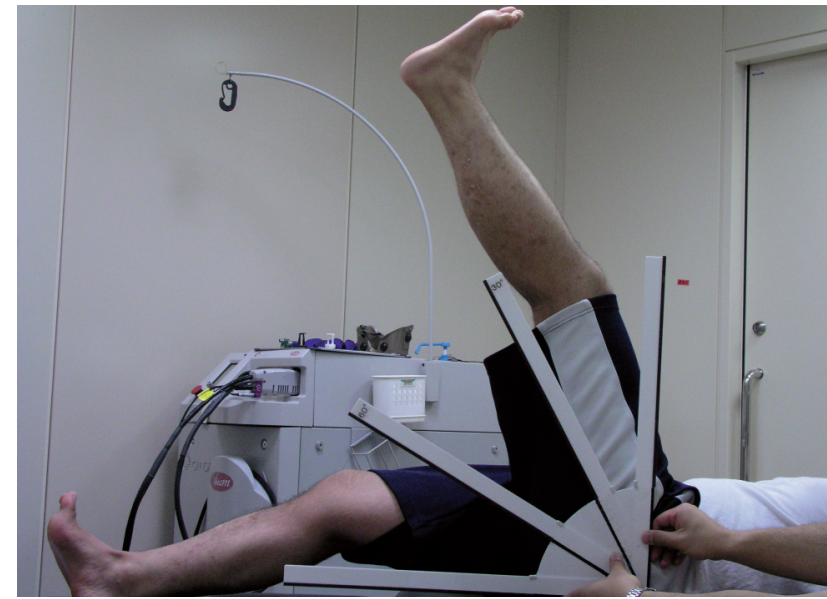

(b): ROM of the left hip joint improved to approximately $80^{\circ}$ after LLLT.

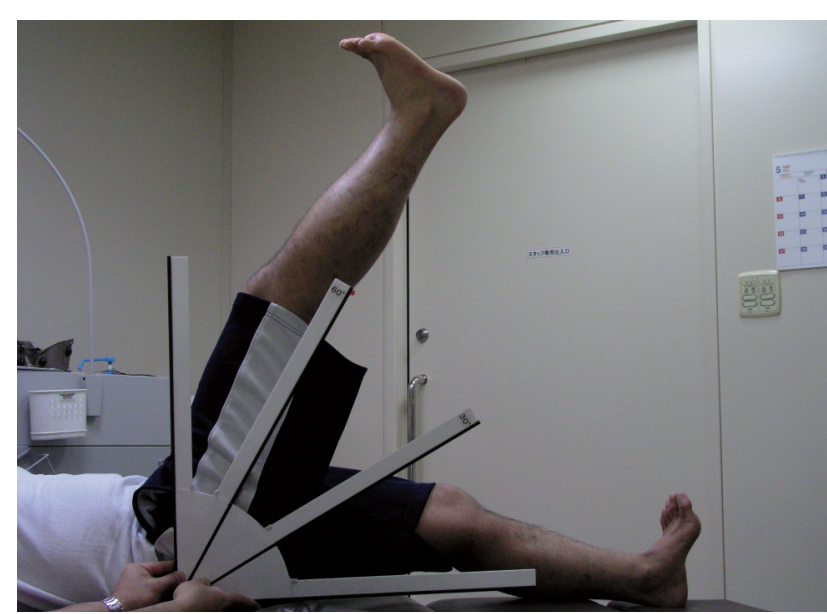

(d): ROM of right hip joint improved to approximately $80^{\circ}$ after LLLT.

Fig. 3: ROM measurements at baseline and after the final LLLT session in both left and right hip joints.

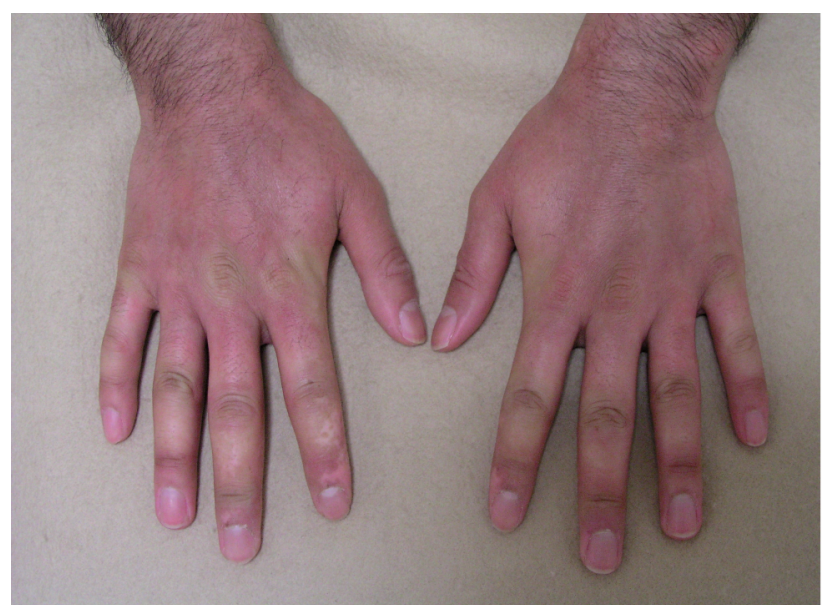

(a): Erythema of his hands before LLLT.

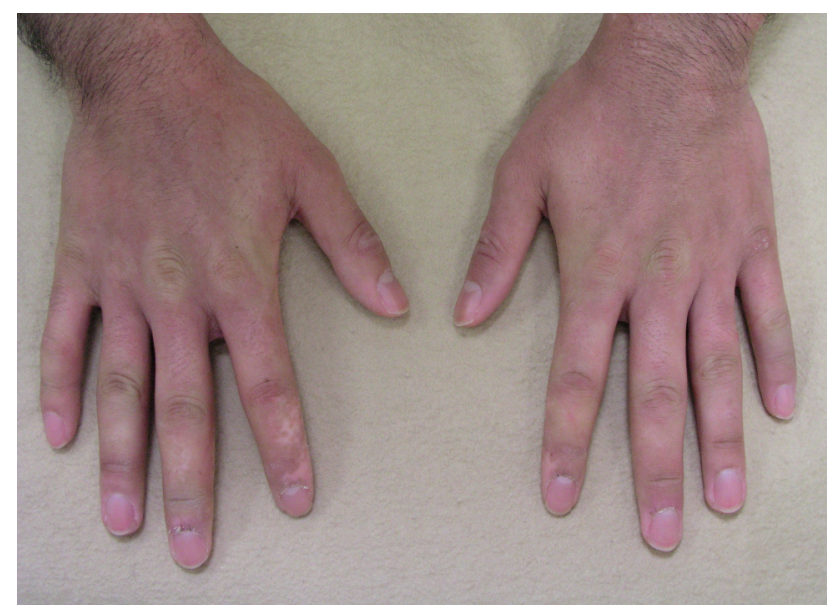

(b): Erythema decreased after LLLT.

Fig. 4: LLLT-mediated Improvement in erythema of the hands. 


\section{Subject and Methods}

\section{Subject}

The patient first noticed Raynaud's phenomenon in the winter of 2002; he had also noticed skin thickening by that time. In the spring of 2003 an ulcer appeared on the tip of one of his right fingers which took one month to heal. Interstitial pulmonary fibrosis was incidentally evident on a chest X-ray during a health check in the autumn of 2004. In additional, immunochemical findings showed positive for the anti-Scl-70 antibody, and at that time the patient was diagnosed as having systemic sclerosis under the criteria of the American Rheumatism Association Diagnostic and Therapeutic Criteria Committee ${ }^{(20)}$.

From February 2006 bosentan was prescribed for preventing progression of the interstitial pulmonary fibrosis $(21,22)$, initially at $62.5 \mathrm{mg}$ twice a day and then one month later at $125 \mathrm{mg}$ twice a day. In addition to bosentan, LLLT was added for improvement of the peripheral blood circulation and overall disease status from July 2006. Written informed consent was obtained from the patient for all treatments.

\section{Laser irradiation}

The LLLT system used was an $830 \mathrm{~nm}$ GaAlAs diode laser (60 mW, continuous wave, incident power density $3 \mathrm{~W} / \mathrm{cm}^{2}$ ). The patient was irradiated for $20 \mathrm{~min}$ on the neck (incident energy density or radiant flux per point of $\left.3600\left(3 \mathrm{~W} / \mathrm{cm}^{2}, 1200 \mathrm{sec}\right) \mathrm{J} / \mathrm{cm}^{2}\right)$ following the proximal priority technique ${ }^{(5)}$ in a quiet, temperaturecontrolled $\left(23-25^{\circ} \mathrm{C}\right)$ and humidity-controlled (40-50\%) room.

The LLLT was performed in three stages for 24 weeks. In the first stage the irradiation was performed for 6days a week, in the second it was done every other day for two weeks, and in the third stage one treatment session was given per week for the remaining 21 weeks, giving a total of 35 treatments. Treatment was discontinued when both the patient and clinician agreed there was no further improvement seen after the 2 previous treatment sessions, and were satisfied with the result.

Dermal blood circulation was assessed with thermography images before and $5 \mathrm{~min}$ after LLLT. Although there is no gold standard for the measurement of skin blood flow in patients with primary Raynaud's phenomenon or SSC, infrared thermography has been used in several centers (23-26). We examined CT and pulmonary function. Skin tightness was measured with the modified Rodnan total skin thickness score (scale 0-51) (27, 28). The activity, disability, pain, and psychological impact associated with Raynaud's phenomenon were evaluated using a proposed core set of outcome measures for studying Raynaud's phenomenon in SSC patients (29). These measures included the Health Assessment Questionnaire Disability Index (scale 0-3) (30-34), visual analog scales (VAS) for Raynaud's phenomenon, digital ulcers, pain, and overall disease (scale of 0-3), a VAS for the physician's global assessment of health (scale 0-3), and the mood and tension scales of the Arthritis Impact Measurement Scale 2 (scale 0-10) (35)

\section{Results}

After every LLLT session the patient recovered from fatigue and felt warmth. In fact thermography showed an improvement of skin blood flow 5 min after LLLT (Fig. 1). This improved skin blood flow continued even four months after he had finished the series of LLLT treatments (Fig. 2). LLLT alleviated the edema, muscle tension and skin tightness, and the range of motion (ROM) of his hip joints showed significant improvement (both left and right legs, from $30^{\circ}$ baseline to approximately $80^{\circ}$ post treatment) (Fig. 3) Erythema of his hands (Fig. 4) also improved. The patient noticed a significant improvement in his Raynaud's phenomenon symptoms in both frequency and duration which is clearly seen on Patient's assessment by VAS (Table 1). Skin tightness was improved as shown in the skin score (Fig. 5). The disability from joint and skin tightness did not get worse (Table 1). There was no progression of pulmonary fibrosis seen on computer tomography (data not shown) and pulmonary function (\%VC and \%DLCO) remained stable with no deterioration (Table 1). The patient did not experience any adverse events during his LLLT sessions. In addition to the above results the patient's mood scores also improved as shown in the AIMS2 tension scale and AIMS2 mood scale (Table 1).

\section{Discussion}

SSC is a multisystem disease classically characterized by inflammation, fibrosis, and a diffuse vasculopathy. Many investigations have shown that. LLLT particularly at $830 \mathrm{~nm}$ is effective in alleviating all of these symptoms. Firstly there were many reports about the antiinflammatory effect of LLLT ${ }^{(9-12)}$. For example, LLLT reduced the inflammatory cell migration in acute inflammatory mouse pleurisy induced by carrageenan (13) and inflammatory mouse knee joints ${ }^{(14)}$. In LLLT in human subjects, it has been reported to reduce the 


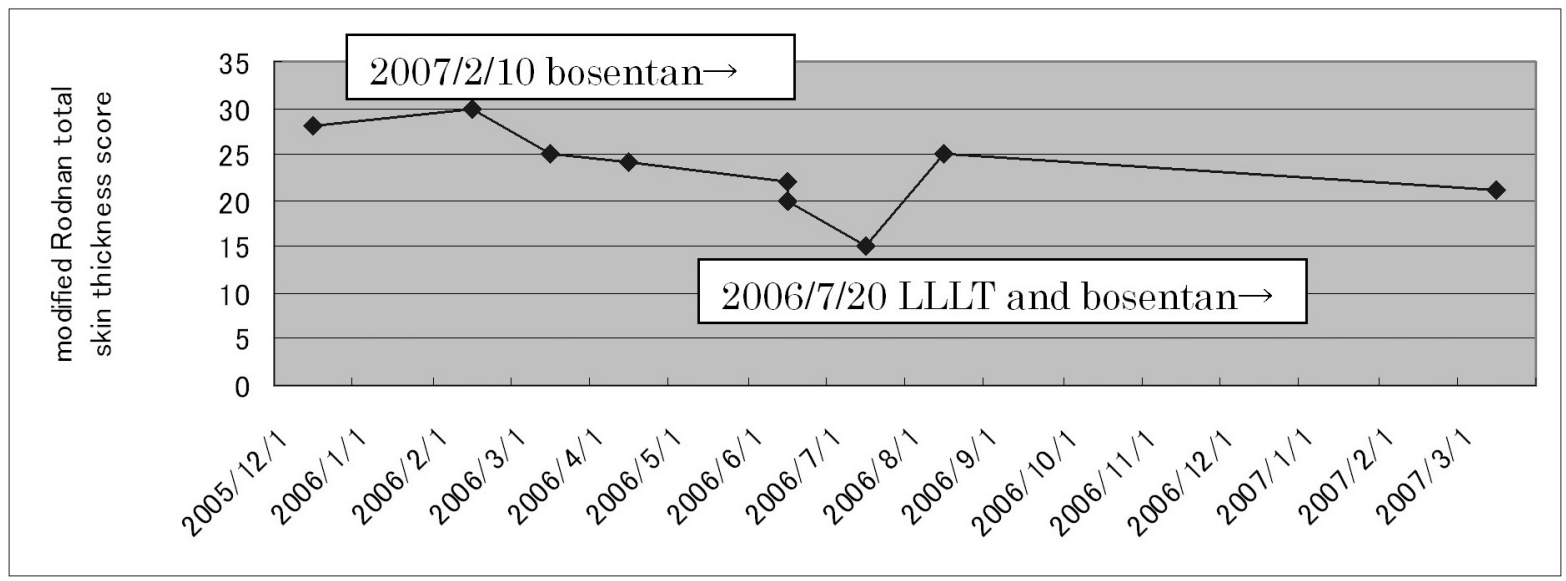

Fig. 5: Modified total Rodnan skin thickness score compared for bosentan alone and bosentan with adjunctive LLLT with a GaAlAs diode laser.

Table 1: Subjective and objective assessments of various aspects of SSC disease-related symptoms. Scales are as shown below the table

\begin{tabular}{|c|c|c|c|}
\hline Date & \multicolumn{3}{|c|}{$\begin{array}{l}\text { bosentan started } \rightarrow \\
\text { LLLT started } \rightarrow\end{array}$} \\
\hline Raynaud's phenomenon, patient's assessment by VAS (0-3) & 3.8 & 0 & 0.48 \\
\hline Disital ulcers scale, patients assessment by VAS (0-3) & 0 & 0 & 0 \\
\hline \multicolumn{4}{|l|}{ Psychological scales } \\
\hline AIMS2 tension scale (0-10) & 4.4 & 3.6 & 2.4 \\
\hline AIMS2 mood scale (0-10) & 2.8 & 2.7 & 2.4 \\
\hline \multicolumn{4}{|l|}{ Disability and global measures } \\
\hline HAQ DI (0-3) & 0.38 & 0.38 & 0.38 \\
\hline Patient's global assessment by VAS (0-3) & 0.32 & 0.42 & 0.18 \\
\hline Physician's global assessment by VAS (0-3) & 0.8 & 0.6 & 0.3 \\
\hline Pain scale, patient's assessment by VAS (0-3) & 0 & 0 & 0 \\
\hline Modified Rodnan total skin thickness score (scale 0-51) & 30 & 20 & 21 \\
\hline \multicolumn{4}{|l|}{ Lung function } \\
\hline \%VC (\%) & 52 & 50 & 54 \\
\hline$\%$ DLCO $(\%)$ & 35.2 & 34.7 & 34.0 \\
\hline
\end{tabular}

VAS=visual analog scale; AIMS2=Arthritis Impact Measurement Scale 2;

HAQ DI=Health Assessment Questionnaire Disability Index

postsurgical levels of C-reactive proteins in patients ${ }^{(15)}$, orthodontic post-adjustment inflammation (16) and inflammatory of activated Achilles tendinitis (17). LLLT shortened the inflammatory phase on skin wound healing in rats (18). Secondly LLLT causes potent dilation in laser-irradiated arterioles, which was shown to lead to marked increases in the arteriolar blood flow (6-8).
Lastly LLLT reduced fibrosis in traumatized Achilles tendons in the rat model (19).

In this patient skin blood flow and body temperature increased $5 \mathrm{~min}$ after the first LLLT session, and they remained at an elevated level even before the final LLLT session, which was 7 days after the previous penultimate treatment. The patient reported noticing 
remarkable improvement of his Raynaud's phenomenon-associated symptoms as treatment progressed. SSC-related vasculopathy is irreversible and it is rare in the natural course of the disease that the skin blood flow improves dramatically within a year. The improvement in the present study was thus thought to be due to the combination of LLLT and bosentan. Bosentan is a dual endothelin antagonist, which specifically expands the pulmonary artery and is used for pulmonary hypertension, but there are very few reports that bosentan is capable of vasodilation in the peripheral arteries of the fingers and thus improves digital blood circulation (21), therefore the addition of LLLT in our study is the only possible explanation for this phenomenon.

SSC demonstrates a varied prognosis. Generally the skin tightness progresses (i.e., the skin score increases) during the first five years, then the skin gradually softens (the skin score decreases). The higher the maximum skin score is, the lower the survival rate of the affected patient and an increase in the skin score is related to renal insufficiency, pulmonary fibrosis and cardiopathy (36). At the point of initiation of

\section{References}

1: Baron M, Lee P, Keystone EC (1982): The articular manifestations of progressive systemic sclerosis (scleroderma) . Ann Rheum Dis. 41: 147-52

2: Seibold JR. Scleroderma. In: Ruddy S, Harris ED, Sledge CB, editors (2001). Kelley's textbook of rheumatology. Philadelphia: W.B. Saunders: 121139

3: Seibold JR, Clements PJ, Furst DE: Treatment of systemic sclerosis by disease modifying agents. Systemic Sclerosis. Clements PJ, Fuest DE (eds), p535-548, Williams \& Wilkins, 1996

4: Seibold JR, Furst DE, Clements PJ (1992) : Why everything (or nothing) seems to work in the treatment of scleroderma. J Rheumatol. 19: 673-676

5: Ohshiro T (2005) :The Proximal Priority Technique: How to maximize the efficacy of laser therapy. Laser Therapy.14:121-128

6: Kubota J (2002):Effects of diode laser therapy on blood flow in axial pattern flaps in the rat model. Lasers Med Sci. 17 (3):146-53.

7: Maegawa Y, et al (2000): Effects of near-infrared low level laser irradiation on microcirculation. Lasers Surg Med. 27: 427-437

8: Kubota J, et al (1996): The effects of diode laser LLLT on flap survival. Laser Therapy. 8: 241-246

9: Freitas AC, Pinheiro AL, Miranda P, Thiers FA,
LLLT in the present study, at least three years had passed since the first onset of SSC, therefore the data sagest that the adjunctive treatment of LLLT applied with bosentan was apparently beneficial, it cannot be ruled out that the improvement of skin tightness in the patient in the present was due to the combination treatment with bosentan and LLLT, or it was due simply to the natural course of the disease. A further study in a larger population with earlier onset of SSC is therefore warranted.

\section{Conclusions}

An SSC patient was treated with the combination of bosentan and LLLT for 24 weeks, after which the skin tightness and Raynaud's phenomenon-associated symptoms improved, pulmonary fibrosis did not progress and pulmonary function did not get any worse. Our data from this single case suggest that the addition of LLLT to bosentan was effective for improving both the blood circulation and the overall disease status. Although this was a single case, the good results warrant further study.

Viera AL (2001): Assessment of anti-inflammatory effect of 830nm laser light using C-reactive protein levels. Braz Dent J. 12 (3): 187-90

10: Gal P, Vidinsky B, Toporcer T, Morky M, Mozes S, Longauer F, Sabo J (2006): Histological assessment of the effect of laser irradiation on skin wound healing in rats. Photomed Laser Surg. 24 (4): 480-8

11: Lopes Martins RA, Albertini R, Martins PS, Bjordal JM, Faria Neto HC (2005): Spontaneous effects of low-level laser therapy $(650 \mathrm{~nm})$ in acute inflammatory mouse pleurisy induced by carrageenan. Photomed Laser Surg. 23 (4): 377-81

12: Moriyama Y, Moriyama EH, Blackmore K, Akens MK, Lilge L (2005): In vivo study of the inflammatory modulating effects of low-level laser therapy on iNOS expression using bioluminescence imaging. Photochem Photobiol. 81 (6):1351-5

13: Yamaguchi M, Kasai K (2005): Inflammation in periodontal tissues in response to mechanical forces. Arch Immunol Ther Exp (Warsz). 53 (5): 388-98

14: Amano A, et al (1994): Histological studies on the rheumatoid synovial membrane irradiated with a low energy laser. Lasers Surg Med.15 (3):290-4.

15: Bjordal JM, Lopes-Martins RA, Iversen VV (2006) :A randomized, placebo controlled trial of low level 
laser therapy for activated Achilles tendintis with microdialysis measurement of peritendinous prostaglandin E2 concentrations. Br J Sports Med. 40 (1): 76-80

16: Medrado AR, Pugliese LS, Reis SR, Andrade ZA (2003): Influence of low level laser therapy on wound healing and its biological action upon myofibroblasts. Lasers Surg Med. 32 (3): 239-44

17: Aimbire F, Albertine R, de Magalhaes RG, Lopes Martins RA, Castro-Faria-Neto HC, Zangaro RA, Chavantes MC, Pacheco MT (2005):Effect of LLLT Ga-AL-As $(685 \mathrm{~nm})$ on LPS-induced inflammation of the airway and lung in the rat. Lasers Med Sci.20 (1): $11-20$

18: Albertini R, Aimbire FS, Correa FI, Ribeiro W, Cogo JC, Antunes E, Teixeira SA, De Nucci G, CastroFaria-Neto HC, Zangaro RA, Lopes-Martins RA (2004): Effects of different protocol doses of low power gallium-aluminium-arsenate (Ga-Al-As) laser radiation $(650 \mathrm{~nm})$ on carrageenan induced rat paw oedema. J Photochem Photobiol B. 74 (2-3):101-7

19: Fillipin LI, Mauriz JL, Vedovelli K, Moreira AJ, Zettler CG, Lech O, Marroni NP, Gonzalez-Gallego J (2005): Low-level laser therapy (LLLT) prevents oxidative stress and reduces fibrosis in rat traumatized Achilles tendon. Lasers Surg Med. 37 (4): 293300

20: Subcommittee for scleroderma criteria of the American Rheumatism Association Diagnostic and Therapeutic Criteria Committee (1980): preliminary criteria for the classification of systemic sclerosis (scleroderma). Arthritis Rheum. 23: 581-590

21: J.DUNNE (2006): Treatment of severe Raynaud's phenomenon with bosentan in a patient with systemic sclerosis. Rheumatology. 45: 911-912

22: Lin At, Clements PJ, Furst DE (2003) Update on disease-modifying antirheumatic drugs in the treatment of systemic sclerosis. Rheum Dis Clin North Am. 29 (2):409-426

23: Kyle V, Parr G, Salisbury R, Thomas PP, Hazleman B, (1985): Prostaglandin E1 vasospastic disease and thermography. Ann Rheum Dis. 44:73-78

24: Darton K, Black CM (1991): Pyroelectric vidicon thermography and cold challenge quantify the severity of Raynaud's phenomenon. $\mathrm{Br} J$ Rheumatol. 30: 190-195

25: O'Reilly D, Taylor L, EI-Hadidy K, Jayson MIV (1992): Measurement of cold challenge responses in primary Raynaud's phenomenon and Raynaud's phenomenon associated with systemic sclerosis. Ann Rheum Dis 51:1193-1196

26: Clark S, Hollis S, Campbell F, Moore T, Jayson M, Herrick A (1999) :The disital-dorsal difference as a possible predictor of secondary Raynaud's phenomenon. J Rheumatol. 26: 1125-1128

27: Clements PJ, Lachenbruch PA, Seibold JR, et al (1993) : Skin thickness score in systemic sclerosis; an assessment of interobserver variability in 3 independent studies. J Rheumatol . 20: 1892

28: Clements PJ, Lachenbruch PA, Seibold JR, et al (1995) : Inter and intraobserver variability of total skin thickness score (modified Rodnan TSS) in systemic sclerosis. J Rheumatol . 22: 1281

29: Merkel PA, Herlyn K, Martin RW, et al. (2002): Measuring disease activity and functional status in patients with scleroderma and Raynaud's phenomenon. Arthritis Rheum. 46: 2410-20

30: Fries JF, Spitz P, Kraines RG, Holman HR (1980) :Measurement of patient outcome in arthritis. Arthritis Rheum. 23: 137-45

31: Steen VD, Medsger TA Jr. (1997): The value of the Health Assessment Questionnaire and special patient-generated scales to demonstrate change in systemic sclerosis patients over time. Arthritis Rheum. 40: 1984-91

32: Poole JL, Steen VD (1991): The use of the Health Assessment Questionnaire (HAQ) to determine physical disability in systemic sclerosis. Arthritis Care Res. 4: 27-31

33: Johnson SR, Hawker GA, Davis AM (2005): The Health Assessment Questionnaire Disability Index and Scleroderma Health Assessment Questionnaire in scleroderma trials: an evaluation of their measurement properties. Arthritis Rheum. 53: 256-62

34 : Khanna D, Furst DE, Clements PJ, et al. (2005): Responsiveness of the SF-36 and the Health Assessment Questionnaire Disability Index in a systemic sclerosis clinical trial. J Rheumatol. 32: 832-40

35: Meenan RF, Mason JH, Anderson JJ, Guccione AA, Kazis LE (1992): AIMS2: the content and properties of a revised and expanded Arthritis Impact Measurement Scales health status questionnaire. Arthritis Rheum. 35:1-10

36: Black CM (1995) :Measurement of skin involvement in scleroderma. J Rheumatol. 22: 1217 